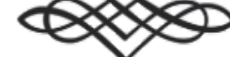

Approaches to violence and public security, towards an ethical-relational perspective based on care.

\title{
Abordajes de la violencia y la seguridad pública, hacia un enfoque ético-relacional basado en el cuidado
}

\author{
Claudia Liliana Perlo \\ Instituto Rosario de Investigaciones en Ciencias de la Educación-CONICET/UNR \\ Diego Carmona Gallego \\ Instituto Rosario de Investigaciones en Ciencias de la Educación-CONICET/UNR \\ DOI: https://doi.org/10.15366/bp2021.27.012 \\ Bajo Palabra. II Época. № 27. Pgs: 231-256
}


Recibido: 22/07/2020

Aprobado: 07/05/2021

\section{Resumen}

El propósito de este trabajo es brindar una perspectiva teórica en torno a la prevención de la violencia y la seguridad, problema relevante en nuestra sociedad actual, que posibilite repensar e incidir en las políticas públicas vigentes. Los desarrollos teóricos aquí presentados son emergentes de nuestro trabajo de campo. Se trata de estudios cualitativos de corte etnográfico, en diversos territorios sociocomunitarios en la ciudad de Rosario, Santa Fe, Argentina. Los mismos se llevaron a cabo entre los ańos 2014-2019 y giraron en torno a los problemas de prevención de la violencia, seguridad, políticas y prácticas de cuidado. En tales estudios advertimos tres abordajes de la seguridad desde la política pública. Los mismos soportan diferentes sustentos ontoepistemológicos que analizaremos en este artículo. Los hemos reunido en tres categorías: abordaje represivo-punitivo, centrado en el control y la prevención del delito; abordaje de la restitución de los derechos, basado en garantizar la igualdad socioeconómica y cultural $y$ el abordaje ético-relacional propuesto en este trabajo que busca dar un giro a este crónico problema, apostando a la reparación de los vínculos a través del cuidado de sí y el cuidado del otro. En este trabajo abordaremos la inseguridad como modo relacional constitutivo de las sociedades modernas. Profundizaremos en la concepción de cuidado, y la pondremos en relación y en tensión con el concepto de seguridad. Finalmente, presentamos apreciaciones finales que dan cuenta de nuestros hallazgos de investigación, conducentes a replantear las políticas públicas sobre la cuestión.

Palabras clave: violencia; seguridad; ética del cuidado; políticas públicas.

\section{Abstract}

The aim of this work is to provide a theorical perspective on the prevention of violence and security, which are relevant problems in our current societies, that give some possibilities to rethink and influence current public policies about this issue. The developments presented here emerge from our field work. These are qualitative ethnographic studies in various socio-community territories in the city of Rosario, Santa Fe, Argentina. They were carried out between the years 2015-2019 and were related with violence prevention, security, and care policies-practices. In such studies we have seen three approaches to security from public policy. They hold different perspectives on ontoepistemological issues that we will analyze in this article. We have clasified them into three categories: repressive-punitive approach, focused on the control and prevention of crime; approach to the restitution of rights, based on ensuring socioeconomic and cultural equality; and the ethical-relational approach, which we propose in this work and seeks to change this chronic problem in care for the other. In this work we will address insecurity as a constitutional relational mode of modern societies. We will delve into the concept of care, and we will analyze it in relation and in tension with the idea of security. Lastly, we present final observations from our research findings leading to rethink public policies on the issue.

Keywords: violence; security; ethics of care; public politics. 


\section{Introducción}

El ABORDAJE HEGEMÓNICO DE LA SEGURIDAD, se asienta en el supuesto de que el problema de la violencia está directamente vinculado a grupos sociales específicos, excluidos del sistema socio-productivo y del sistema educativo formal. Son varios los indicadores que lo sostienen, la construcción del mapa rojo o del calor, que discrimina territorios de mayor o menor peligrosidad, la militarización de los barrios de menores recursos socio-económicos, como así también datos estadísticos oficiales. Si revisamos la información que proporciona el Sistema Nacional de Estadísticas de Ejecución de la Pena ${ }^{1}$ este supuesto parece encontrar la profecía auto-cumplida; la población en contextos de encierro está compuesta mayoritariamente por hombres, jóvenes, solteros, desocupados, de sectores de la periferia urbana, con baja escolaridad y sin capacitación laboral. Las políticas públicas han buscado dar soluciones a este problema fundamentalmente a través de dos respuestas que se consideran complementarias. Una de ellas, responde a un modelo represivo-punitivo que a través del discurso del "combate de la violencia", ejerce control y castigo sobre el grupo social involucrado y estigmatizado. La represión de unos se asienta en el miedo y la protección de otros. Desde este modelo, los derechos de seguridad y libertad y las personas mismas, se encuentran enfrentadas. La otra respuesta articulada con la primera, responde a un modelo de justicia social, abocada a la "restitución de derechos" a través del mejoramiento de infraestructura y cobertura de la carencia en relación a la vivienda, la salud, la educación y el trabajo para los grupos excluidos del sistema. Estas dos propuestas acogen el supuesto de que las personas que tienen garantizados sus derechos básicos no van a delinquir y que si además el Estado muestra "mano dura" con los que se desvían de la ley, podrá restituirse la paz social. Consideramos que estos modelos pueden ser necesarios en un momento de urgencia social, pero de ningún modo suficientes y menos aún el eje de las políticas públicas dentro de un marco social democrático. En un estado de derecho, "recurrir a las armas" o "restituir derechos" que muchas veces el propio Estado ha incumplido, deja a las claras la necesidad de pensar otros modelos. Esta revisión implica sumergirnos en los orígenes de lo humano y en los modos de relacionarnos que nos configuraron como tales.

\footnotetext{
${ }^{1}$ Nos referimos a los informes elaborados por la Dirección Nacional de Política Criminal en Materia de Justicia y Legislación Penal, del Ministerio de Justicia y Derechos Humanos de la República Argentina. Se puede hacer consulta de las mismas en http://www.saij.gob.ar/estadisticas-ejecucion-de-la-pena
} 
Si bien el problema de la inseguridad pareciera ser un tema incipiente y emergente de la modernidad, lo cierto es que nos remonta a los orígenes de los primeros agrupamientos humanos. A partir de una reconstrucción histórica, el biólogo cultural Maturana ${ }^{2}$ describe como fuente de la inseguridad en los humanos un modo de vivir que surge con el pastoreo y se funda en la competencia con el lobo como comensal natural. En otras palabras, desde el momento en que el hombre mata al lobo para evitar que éste coma su ganado, surge un emocionar específico, el de la inseguridad. Un emocionar de continua atención-concentración para proteger a la manada frente al lobo. Maturana establece así una relación entre inseguridad, apropiación, competencia y enemistad, constelación de sentidos y prácticas que abonan la violencia. Para el autor, nuestros pensamientos hallan su fundamento en las emociones, que a su vez no están desligadas de las tramas sociales en las que participamos.

Los seres humanos en su convivencia sensorial-operacional-relacional ${ }^{3}$ articulan con determinadas emociones, definen modos de vida y de habitar la experiencia. Estas referencias que introducimos nos permiten preguntarnos en los albores del siglo XXI: ¿Cuáles son las disposiciones emocionales que están presentes en el abordaje de la seguridad como punición y control? ¿Qué emociones canaliza, genera y reproduce este abordaje? ¿Cómo es posible la hegemonía de este abordaje dentro de un marco político democrático?

\section{Diversos abordajes de la prevención de la violencia}

\subsection{Abordajes basados en la seguridad}

\subsubsection{Abordaje represivo-punitivo}

Se trata de un abordaje basado en el control que entiende a la seguridad en términos de protección de unos respecto a otros. El supuesto de este enfoque encuentra sus raíces en el contrato social. Esta es la gran metáfora con la que los teóricos sociales pensaron la vida moderna. Thomas Hobbes, filósofo fundante del pensamiento moderno, designaba al Estado como el encargado de asegurar la convivencia dada una supuesta inclinación natural de los seres humanos a la destrucción. El Estado es pensado por el filósofo como un Dios mortal. "El Estado asume el lugar de Dios, y las personas deben manifestar ante éste miedo, asombro

\footnotetext{
${ }^{2}$ Maturana, Humberto y Verden- Zöler, Gerda, Amor y Juego: Fundamentos olvidados de lo humano. Desde el patriarcado a la democracia, Buenos Aires, Granica, 2011.

3 Maturana, Humberto y Dávila, Ximena, El árbol del vivir, Santiago de Chile, MVP Editores, 2015.
} 
y temor reverencial" ${ }^{4}$. De manera convergente, la Declaración Universal de los Derechos Humanos sostiene que todas las personas nacen libres e iguales en dignidad y derechos y deben comportarse resguardando dicho contrato.

Según Foucault ${ }^{5}$ el poder de castigar hacia quienes transgredan el contrato constituye una función general de la sociedad, que en la modernidad quedó a cargo del Estado. La suscripción al contrato implica la delegación del poder de las personas hacia el Estado, quien de ahora en más tendrá la función de controlar, en términos de Foucault ${ }^{6}$ vigilar y castigar. De este modo, el Estado basándose en el contrato social (derecho) organiza procedimientos en pos de garantizar la justicia y el orden social.

Como señalamos en la introducción, en nuestro contexto actual, estos procedimientos generalmente están dirigidos a ciertos grupos sociales estigmatizados, haciendo responsables directos de la inseguridad por un lado, a las personas que reúnen una serie de características (bajos recursos, con poca educación y sin trabajo) y por el otro, al Estado como quien debe eliminarla. El castigo, la disciplina, y la existencia de leyes que deben cumplirse, es lo que posibilitaría una sociedad en convivencia. La prevención del delito, la tolerancia cero, la mano dura y las cámaras de seguridad que forman parte del paisaje urbano, constituyen a las claras una postura política antropocéntrica basada en una seguridad externa por fuera de la trama, enfrentando a los unos y a los otros. Esta concepción de seguridad se tensiona y se enfrenta con el concepto de libertad. Estar seguros y sentirse libres para algunos, implica la reclusión de otros. De este modo, el miedo, la desconfianza y la configuración del otro como enemigo, provoca aislamiento, reclusión y autorestricción de deambulación en la vida pública. En definitiva, la seguridad se presenta a costas de la libertad.

Se trata de un abordaje que combina dos estrategias: el refuerzo del sistema represivo institucional y el incremento de la seguridad privada, donde el miedo y la desconfianza constituyen modos relacionales dominantes. De este modo, el miedo y la desconfianza de unos justifica la represión de otros. Los derechos de seguridad y libertad y las personas mismas, se encuentran enfrentadas. Se apela así a una subjetividad victimista ${ }^{7}$ que delega toda la responsabilidad en el Estado, el que responde con controles que se multiplican para garantizar la seguridad, obteniendo paradójicamente los resultados contrarios, violencia. "La víctima critica, pero no emprende

\footnotetext{
4 Sebesta, L. "Raíces de la violencia: para una nueva genealogía, de Hobbes a Marx", América Latina, tiempos de violencias, coordinado por Waldo Ansaldi y Verónica Giordano, Buenos Aires, Ariel, 2014, pp 62-83.

5 Foucault, Michel, Vigilar y castigar, Buenos Aires, Siglo XXI Editores, 1976.

${ }^{6}$ Foucault, Michel, Vigilar y castigar, op. cit.

7 Amador Fernandez Savater "Tener la necesidad de que la gente piense", Interferencias (blog), El Diario, 21 de septiembre de 2018, https://www.eldiario.es/interferencias/izquierda-pensamiento_132_2752106.html
} 
un proceso de cambio; considera a algún Otro culpable de todos sus males; delega sus potencias en 'salvadores' a cambio de seguridad, orden, protección" ${ }^{8}$

Este modelo, en tanto el Estado se erige como garante de la libertad individual y la seguridad pública, se corresponde con los derechos de primera generación, también llamados derechos burgueses, surgidos en el siglo XVIII al calor de la Revolución Francesa. Esto es, derecho a la libertad de opinión, de prensa, de conciencia, resistencia a la opresión y a la propiedad privada. Y respecto a esta última, en relación con lo que venimos planteando en torno a la subjetividad victimista, observamos un Estado liberal garante que protege las libertades de unos, descuidando la de otros, y peor aún, la de la trama social en su totalidad.

Desde este abordaje la metáfora del combate se constituye en la principal estrategia que implica procedimientos de represión y punición para eliminar las "conductas desviadas".

El abordaje hegemónico respecto a esta problemática, sitúa la "lucha contra la inseguridad" como principal estrategia para disminuir la violencia.

Desde el paradigma tanto científico como social ${ }^{9}$ este abordaje responde a una cosmovisión mecanicista, en tanto da respuesta al problema desde la parte-engranaje, la "pieza anómala" que sería necesario reemplazar y/o eliminar. Esta perspectiva reduccionista ignora la dimensión sistémica del problema que permitiría pensar el "desvío" como emergente de un sistema total y complejo. Se trata de una ontología individualista ciega a la trama que desconoce el carácter relacional de todo lo vivo. Esta perspectiva conduce a conductas de aislamiento, que refuerzan una idea de soberanía, basada en la ilusión de separación.

Desde las perspectivas teóricas en torno al cuidado que venimos estudiando, este abordaje de la seguridad obstaculiza el cultivo de los vínculos emergentes de la trama. Es más, inhibe la memoria de la especie, alojada en el inconsciente vital ${ }^{10}$. Esto es, la expresión de los instintos gregarios, intra-especie, conducentes a la solidaridad y el cuidado.

\subsubsection{Abordaje de la restitución de derechos}

EL SEGUNDO ENFOQUE CONCIBE A LA VIOLENCIA como emergente de desigualdades socioeconómicas y culturales. En este marco, se afirma que el rol del Estado consiste en garantizar la efectivización de los derechos de las personas. Este modelo respon-

\footnotetext{
8 Amador Fernandez Savater "Tener la necesidad de que la gente piense", op. cit.

9 Capra, Fritjof, La trama de la vida: una nueva perspectiva de los sistemas vivos, Barcelona, Anagrama, 2010.

${ }_{10}$ Toro Araneda, Rolando, Biodanza, Santiago de Chile, Cuarto propio, 2007.
} 
de a los derechos de segunda generación, esto es derechos económicos, sociales y culturales, ligados al trabajo, la educación y la cultura. El Estado adquiere aquí un rol activo y así como los derechos de primera generación respondieron al ideario de la libertad, proclamado por la Revolución Francesa, los derechos de segunda generación se componen en torno al ideario de igualdad.

Este ideario jurídico de igualdad logra encarnarse en las políticas orientadas a la justicia social que se concretan en los derechos sociales ya durante la primera mitad del siglo XX.

En cierto sentido, esta política se complementa con el modelo punitivo-represivo dirigiéndose a determinados sectores sociales históricamente estigmatizados, que en el primer modelo funcionando como "chivo expiatorio" eran sujetos de delito y aquí son sujetos de derecho. Sujetos también de subestimaciones y generalizaciones que impiden apreciar sus potencias singulares y colectivas. Dicha complementariedad cobija el supuesto que en la medida que los derechos de segunda generación estén garantizados no se producirá el delito. Se promueven inversiones estatales en políticas de salud, educación, construcción de viviendas, proyectos culturales y obras de infraestructura urbanas como cloacas, agua potable, iluminación, apertura de calles. De esta manera, se asegura que destinando mayor inversión estatal en estos aspectos, particularmente hacia los sectores definidos como vulnerables, la violencia disminuirá. En síntesis, las políticas públicas de seguridad basadas en la restitución de derechos, están centradas en la prevención de la violencia y el delito.

Podemos decir que, aunque este segundo abordaje sin dudas complejiza la noción de seguridad ampliándola a las condiciones de vida de las personas, al mismo tiempo comparte con el primer abordaje la noción de seguridad dicotómica y reduccionista que define a unos y a otros desconociendo la perspectiva sistémica de la trama.

Este segundo modelo, si bien podría resultar compatible con un abordaje relacional de la seguridad, desconoce las dimensiones afectivas comprometidas en esta problemática: el miedo, la desconfianza y la competencia entre las personas. Las mismas no se atienden logrando mayores niveles de equidad y de reducción de las desigualdades socioeconómicas.

La justicia social que garantiza los derechos de segunda generación basados en la lógica distributiva son insuficientes para lograr una sociedad cohesionada basada en una rica densidad de vínculos. En definitiva, se trata de la insuficiencia de una ética de la justicia basada en la competencia de derechos y principios abstractos, que no resuelve la compleja problemática de la violencia. Aunque necesaria, esta ética no es suficiente para formular una política que habilite, facilite y potencie el cultivo de los vínculos en la compleja trama social. 
Siguiendo a Held ${ }^{11}$ cuando en la sociedad las personas se tratan entre sí exclusivamente con el respeto que requiere la justicia, pero sin otra consideración más que ésta, el tejido social de confianza y solidaridad puede faltar o desaparecer.

Este modelo de restitución de derechos se asienta sobre el supuesto neoliberal individualista y competitivo, en el cual la meta de las personas en la sociedad focalizadas en el éxito, se encuentra en relación a sus posibilidades o limitaciones de capacidad de consumo. Es un enfoque basado en la carencia que puede restringir la identidad de las personas a la obtención de bienes. El "ser alguien" está subsumido al "tener algo": un título, una vivienda, un trabajo digno y estable, credenciales de circulación efectiva que garantice al mercado un eficiente consumidor.

\subsubsection{Convergencias en los abordajes basados en la seguridad}

EN PRIMER LUGAR PODEMOS DECIR que ambos abordajes, tanto el represivo-punitivo como el de restitución de derechos, no deberían considerarse ni exclusivos, ni excluyentes, siendo pertinente indagar en sus interrelaciones. Ambos responden al paradigma del gobierno focalizado en modelizar la realidad, empujándola a través de una estrategia política vertical, piramidal y jerárquica, que pone el mundo sensible y cotidiano de las personas entre paréntesis. Estos abordajes también convergen en la ética de la justicia, basada en principios universales, de base racional por fuera de los vínculos que entablan las personas y con pretensión de objetividad. El abordaje represivo-punitivo ejerce justicia condenando a aquellos que violaron el contrato social, mientras que el abordaje de restitución de derechos ejerce dicha justicia redistribuyendo recursos y servicios, bajo una lógica equitativa que repara situaciones socioeconómicas vulneradas por el propio Estado. En cualquiera de estos abordajes se trata de una misma perspectiva de seguridad pública ciega al "mundo de la vida" ${ }^{12}$, al "cara a cara" ${ }^{13}$ y a las interacciones del "tejido artesanal de las potencias situadas" 14 . Estos abordajes paradójicamente se imponen de modo violento, generando situaciones altamente peligrosas. Las políticas públicas basadas en el control producen un vaciamiento

11 Held, Virginia, The Ethics of Care: Personal, Political, and Global, New York, Oxford University Press, 2004.

12 Schütz, Alfred, Fenomenología del mundo social. Introducción a la sociología comprensiva, Buenos Aires, Paidós, 1972

13 Perlo, Claudia, Aportes del interaccionismo simbólico a las teorías de la organización. Revista Invenio de la Universidad del Centro Latinoamericano, n. 16, ańo 9, 2006, pp. 89-107.

${ }_{14}$ Amador Fernandez Savater "Del paradigma del gobierno al paradigma del habitar: por un cambio de cultura política”, Interferencias (blog), El Diario, 11 de marzo de 2016, https://www.eldiario.es/interferencias/paradigma-gobierno-habitar_132_4122153.html 
de los espacios públicos y la acción comunitaria, generando en las personas, soledad, aislamiento y fragmentación de los vínculos que imposibilitan habitar la experiencia. En síntesis, la ejecución de las políticas públicas en tanto órdenes de arriba hacia abajo, desalientan todo agenciamiento situado y creativo de los reales protagonistas en el territorio. Cabe aclarar que la función del Estado no debe dirimirse sólo en términos de su presencia o ausencia. Sino más bien en qué tipo de presencia se espera de él. Desde una perspectiva compleja ${ }^{15}$ las teorías de la facilitación sistémica permiten vislumbrar un enfoque basado en la "artesanía de contextos" ${ }^{16}$ que posibilitaría pensar un Estado que brinda la forma y no el contenido (containers). Esto es, el continente necesario que garantice, cuide que "algo" acontezca. Brindar las condiciones, propiciar los espacios, sin imponer cómo, cuándo y quienes habitan la experiencia.

Desde estas perspectivas que abonan nuestras investigaciones, entendemos que estas propuestas deben atender a un emergente social altamente fragmentado, que mediante la violencia denuncia a gritos un modelo relacional humano gravemente dañado. Finalmente, el problema de la violencia no se circunscribe al contexto local, nacional y regional, tampoco se restringe a causas de tipo morales o socioeconómicas en torno a la violación de un contrato. Es en este sentido que proponemos profundizar este problema desde un abordaje ético-relacional.

\subsection{Abordaje ético-relacional de la violencia}

Si todos nos damos la manos ¿Quién tomará las armas?

BOB MARLEY

Desde una persPeCtiva ontoepistemológica basada en las teorías de la complejidad, el enfoque sistémico y el principio biocéntrico, proponemos pensar un nuevo abordaje que guarda marcada distancia con los anteriormente descritos. Se trata de un abordaje ético-relacional de la violencia que desplaza el concepto de seguridad y control hacia el concepto de cuidado y reparación de la red social dañada.

Desde esta perspectiva la naturaleza del mundo está signada por la incertidumbre, la interdependencia, la unidad en la diversidad de la totalidad, el azar y el caos,

${ }_{15}$ Morin, Edgar, Introducción al pensamiento complejo, Barcelona, Gedisa, 1998. Ver también Morin, Edgar, Los siete saberes necesarios a la educación del futuro, Caracas, IESALC-UNESCO, 2000.

${ }^{16}$ Fuks, Saul, FSPC: La facilitación sistémica de procesos colectivos. Artesanía de contextos focalizada en la promoción de la creatividad y de los procesos participativos en grupos, comunidades y redes. Revista IRICE, n.20, pp. 63-76. 
la indeterminación, la acausalidad, la sincronicidad y la multidimensionalidad ${ }^{17}$ Es en este sentido que las políticas públicas basadas en la seguridad y sustentadas en la ilusión de control y predicción, ya no encuentran lugar en esta nueva cosmovisión del mundo. Es interesante señalar la convergencia y encuentro del paradigma científico con un modelo social de seguridad basado en la categoría de control. Desde un paradigma reduccionista la categoría de seguridad se contrapone a la de inseguridad ligada al descontrol que emerge como reacción. En términos de políticas públicas la ausencia de represión puede ser entendida como falta de gobierno, por lo que desde este modelo, el miedo del otro se constituye en necesaria estrategia. De modo radicalmente opuesto, desde la perspectiva de los nuevos paradigmas el desorden no constituye una configuración peligrosa, contrariamente significa un vacío fértil ${ }^{18}$, una nueva forma emergente dentro de un viejo orden que ha llegado a su descomposición.

La nueva cosmovisión del mundo nos despierta de la ilusión de control que desde la modernidad viene capturando nuestra percepción, dejando en claro hoy su más vívido fracaso.

A partir de este enfoque de atención a la violencia que proponemos, ya no es posible pensar en términos de víctimas y victimarios. La realidad se entreteje a través de una trama en la cual nosotros, igual que todos los seres vivos, somos hebras fuertemente interconectadas y entrelazadas ${ }^{19}$. La ilusión de separatividad constituye una falacia que obtura apreciar nuestra interdependencia. En el nivel fundamental de la materia ya no existen partes, solo subtotalidades dentro de una unidad-totali$\mathrm{dad}^{20}$. En el nivel fundamental de la conciencia somos uno ${ }^{21}$ Lo hasta aquí expresado nos permite expresar que todas las personas y en términos de sociedad, todos los ciudadanos, somos protagonistas y responsables en la construcción de los vínculos de los que formamos parte. Por lo que las perspectivas basadas en la seguridad en términos de un control externo que un otro puede garantizarnos, ya no puede sostenerse desde los conocimientos acumulados en este momento histórico.

Contrariamente desde la perspectiva que aquí venimos presentando ya no es la inseguridad, sino la incertidumbre, que no significa otra cosa que la ausencia de certeza absoluta, la que constituye el punto nodal para comprender la complejidad de la cuestión que venimos planteando. La incertidumbre que provoca el "desor-

\footnotetext{
${ }_{17}$ Perlo, Claudia, Hacer ciencia en el siglo XXI: Despertar del sueño de la razón, Paraná, Editorial Fundación La Hendija, 2014.

${ }_{18}$ Perlo, Claudia; De la Riestra, María del Rosario, Costa, Leticia. Organización, fragmentación y posibilidades de cambio: la brecha como vacío fértil, Cuadernos Ebape, n. 2, 2010 pp.247-259.

19 Aczel, Amir, Entrelazamiento: el mayor misterio de la física, Barcelona, Editorial Crítica, 2008

20 Böhm, David, La totalidad y el orden implicado, Barcelona, Kairós, 1988.

21 Toro Araneda, Biodanza, op. cit.
} 
den" nos conmina a confiar en un nuevo orden. El abordaje ético-relacional que aquí proponemos se ha despojado del miedo y apuesta a la confianza como su cimiento fundamental. La confianza aquí no se erige en base a ninguna certeza, sino en una apuesta en el vacío de una plena indeterminación. Es en este sentido que entendemos a la confianza, siguiendo a Cohen ${ }^{22}$, en tres dimensiones entrelazadas: Confianza "en sí mismo", la que constituye la afirmación de nuestra identidad y autonomía, confianza "en los demás", la que nos permite reconocernos como co-creadores de la trama intersubjetiva que constituye la vida y la confianza en "el ser en sî", confiar tanto en lo más probable como en lo más improbable, en el ser como devenir.

De este modo, entendemos la confianza en común unidad a través del cultivo y construcción de redes de apoyo mutuo. Como hemos afirmado en trabajos anteriores "la confianza es constitutiva de lo social, sin ella no se llevarían a cabo un sinnúmero de acciones interconectadas necesarias para el desarrollo de la vida" ${ }^{23}$

El abordaje ético-relacional nos recuerda la etimología de seguridad: sine curae ${ }^{24}$ . Es decir, sin cuidado. Si abordamos la violencia desde la seguridad, abandonamos por lo tanto las prácticas de cuidado, como la escucha, la empatía, la atención, la confianza. El cuidado requiere habitar nuestros vínculos, recrear al otro en uno mismo, mientras que la seguridad siempre está dada por el control asegurado desde fuera. Ésta última se propone asegurar una supuesta soberanía y aislamiento en una vida que, por definición, es frágil e interdependiente. Frágil en el sentido de corpórea, expuesta a la afectación de otros, tanto en un sentido positivo, como en el de sufrir una herida, una lesión. Esta condición universal de fragilidad es abordada por las políticas de seguridad pero para buscar eliminarla. Las mismas se sustentan en la creencia de que podemos ser "invulnerables", "intocables", "inconmovibles" dentro de los muros que se construyen para aislarse de lo "peligroso".

La propuesta aquí presentada nos convoca a un desplazamiento: de la seguridad como control externo, estatal o privado, al habitar el cuidado de sí y del otro desde los lazos producidos en la comunidad, el aprendizaje de la afectividad, la confianza y las redes de apoyo mutuo. A partir del cuidado de sí y del otro, la comunidad se da a sí misma un cuidado que no exige "mayor seguridad" ya que la seguridad se solicita cuando ya abdicamos previamente del cuidado ${ }^{25}$. Este abordaje nos permite reconocernos como partícipes y artesanos a través de una actitud de ocupación,

${ }^{22}$ Perlo, Claudia, Hacer ciencia en el siglo XXI: Despertar del sueño de la razón, op. cit.

23 Perlo, Claudia, Hacer ciencia en el siglo XXI: Despertar del sueño de la razón, op. cit., p. 153.

24 Denise Najmanovich, "De la pedagogía de la crueldad a la ecología de los cuidados" (conferencia, VI Congreso de AUDEPP y X Congreso de FLAPPSIP, mayo de 2019).

25 Denise Najmanovich, “Cuidadanía: ecología de los saberes y los cuidados” (conferencia, XVI Jornadas Nacionales de la Red de Psicopedagogía Garrahan, diciembre de 2019). 
responsabilidad y compromiso afectivo ${ }^{26}$ con el otro y con nosotros mismos. En este sentido, identificamos en la dimensión ética y relacional del concepto de cuidado, importantes herramientas para un abordaje democrático de la seguridad, así como un desplazamiento de la delegación de la seguridad a ser parte del cuidado como práctica cotidiana.

Desde el enfoque biocéntrico, el cual concibe al ser humano como hebra de una trama vital, proponemos co-construir un espacio humano centrado en la recuperación del profundo sentido de la vida y su resguardo. Para profundizar en este sentido necesitamos abandonar la perspectiva individualista del yo compelido al "dominio de sî", "seguridad de sí mismo" y el "control de las emociones", posturas abonadas por diversas disciplinas del campo psicosocial, que han confinado el yo y su potencial de interdependencia. De modo radicalmente opuesto, el cuidado de sí y el cuidado del otro se erigen sobre la base de la confianza que ya no implica encierro del yo, sino apertura. Se trata de un yo multirrelacional que construye su identidad en común unidad, pulsando en tensión entre la diversidad, el otro, y su propia singularidad. En términos de Lévinas no nos terminamos de constituir sino en el mutuo reconocimiento y ante la interpelación ética del rostro del otro podemos responder acogiendo la alteridad (cuidado) o reduciéndola a la mismidad (violencia) ${ }^{27}$.

Nos encontramos construyendo un enfoque ontológico, existencial y ético de convivir, vivir con otros. Esta vida con otros no es una elección de la que disponemos libremente, sino el modo mismo en que podemos emerger como singularidades. Evocando a George $\mathrm{Mead}^{28}$ la posibilidad de emergencia del yo es a través de su experiencia de ser y estar en el mundo. En esta coyuntura actual la tarea requiere un fuerte compromiso con la reconstrucción de la trama social-vital. Este enfoque está abocado a trabajar en torno a los derechos de tercera generación, de convivencia armoniosa de las diferencias, de solidaridad, de paz social, donde el otro no es un enemigo, sencillamente es otro.

Nuestra propuesta concreta de trabajo en las organizaciones en torno a la reparación de la trama tiene por eje el desarrollo de la afectividad. Esta tarea plantea una ardua revisión de nuestros vínculos verticalistas basados en la jerarquía, el sometimiento, la competencia, el ego, la idolatría, la descalificación, la crítica siempre destructiva, el debate tosco, el miedo, el resentimiento y el abandono. Gérmenes latentes de la violencia que históricamente han destruído las sociedades humanas y la vida misma. Desde la perspectiva que denominamos biocéntrica, esto es centrada

\footnotetext{
${ }_{26}$ Boff, Leonardo, El cuidado esencial: ética de lo humano, compasión por la tierra, Madrid, Editorial Trotta, 2004

27 Cullen, Carlos, Ética, ¿dónde habitas?, Buenos Aires, Editorial Las cuarenta, 2019

${ }_{28}$ Mead, George, Espiritu, persona y sociedad, Buenos Aires, Paidós, 1972
} 
en la vida, construimos cuidado cuerpo a cuerpo, tejiendo redes saludables de apoyo. En el mundo adulto no necesitamos "protección" frente al "otro", se requiere un urgente compromiso con el cuidado de uno mismo y del semejante. Entendemos que este abordaje implica dar un salto cuántico, que posibilite abandonar nuestros juicios, que limitan nuestra percepción y dificultan el encuentro con la otredad.

\section{El cuidado como actitud y práctica cotidiana.}

\subsection{Concepción de cuidado}

El DeSARRollo del abordaje Ético-relacional de la violencia, exige un recorrido por las nociones de cuidado de sí y cuidado del otro, en las cuáles el mismo ahinca y se sustenta. Por ello indagamos en la dimensión del cuidado en tanto ética (ethos). El término ethos tiene al menos dos significados: remite al modo de relacionarnos, a nuestros hábitos y costumbres, y también a la morada, aquel lugar que construimos y habitamos. En este sentido, el cuidado en tanto ética nos permite dar cuenta de la hospitalidad, el acogimiento del otro en tanto otro singular y diferente.

La ética del cuidado ha sido definida como un modo-de-ser ${ }^{2930}$, cuyo cultivo deberíamos promover en función de expresar una actitud de ocupación, preocupación, responsabilidad y compromiso afectivo con el otro y con la naturaleza. Así como Boff concibe al cuidado sosteniendo que más que un acto, se trata de una actitud-fuente de la cual brotan actos, el filósofo búlgaro Todorov ${ }^{31}$ lo definió como práctica cotidiana. En su estudio en torno a los testimonios de sobrevivientes de campos de concentración del totalitarismo soviético y alemán, identificó prácticas de cuidado existentes que se desarrollaban entre los detenidos. Las mismas permitieron a quienes las ejercieron seguir sintiéndose humanos ante un régimen de deshumanización. El filósofo argentino Cullen establece un anudamiento entre el cuidado de sí y del otro en la noción de estar-siendo. "Esta relación entre el cuidado de sí y el cuidado del otro se anuda profundamente en el equilibrio de lo humano, que consiste en estar-siendo y no en pretender ser sin estar" ${ }^{32}$. Para el especialista,

\footnotetext{
29 Boff, Leonardo, El cuidado necesario, Madrid, Editorial Trotta, 2012

30 Según indica la filósofa Luce Irigaray en su obra $Y o$, tú, nosotras, el término ser se identifica a menudo con el término habitar en la filosofía de Heidegger. "Con esas mismas raíces que significan ser y habitar se relaciona el nombre de Hestia, divinidad femenina encargada de guardar la llama del hogar" (1992:16). Esta diosa de la mitología griega se relaciona con la hospitalidad, el hogar abierto que acoge y recibe, la comensalidad. Es decir, el hogar como una metáfora para designar el acogimiento por parte de un otro.

31 Todorov, Tzvetan, Frente al límite, México, Siglo XXI Editores, 2004

32 Cullen, Carlos, Ética, ¿dónde habitas?, op. cit. p. 295
} 
la ética tiene como fundamento el cuidado del otro en tanto otro. Cuidar al otro, es decir acoger su alteridad sin reducirlo a la mismidad, es la forma más profunda del cuidado de sí.

En tanto el cuidado constituye un vínculo de acogimiento del otro en tanto otro resulta importante pensar esta cuestión más allá de la ética de justicia, referida en los abordajes de la seguridad. En este sentido la perspectiva de Carol Gilligan en torno a la ética del cuidado ha resultado un aporte significativo para nuestros trabajos.

\subsection{De la ética de la justicia a la ética del cuidado desde la perspectiva de Gilligan}

LOS ESTUDIOS DE LA ÉTICA del cuidado presentan como aporte ineludible las investigaciones de Carol Gilligan. Ha sido esta psicóloga norteamericana de la Universidad de Harvard quien fundó la llamada "ética del cuidado" cuestionando las visiones del desarrollo moral hegemónicas. En sus estudios empíricos Gilligan halló dos modos de pensamiento. El primero, al que llamó ética del cuidado, presentaba como características la responsabilidad en las relaciones, la integración de los afectos y la búsqueda del mantenimiento de las conexiones. El segundo, al que llamó ética de la justicia, estaba basado en la evaluación de los comportamientos a partir de conceptos abstractos, formales y universales. ${ }^{33}$

Gilligan encontró la ética del cuidado mayormente en las mujeres, lo que fundamentó como resultado de socializaciones diferentes en los nińos y las niñas en el marco de una cultura patriarcal. A diferencia de la ética de la justicia, el pensamiento basado en la ética del cuidado está inmerso en los detalles de las relaciones así como en los contextos particulares y singulares. El mismo muestra mayor tendencia a adoptar el punto de vista del "otro particular o concreto" ${ }^{34}$. Desde esta perspectiva, el cuidado no depende de una serie de principios abstractos, (el derecho, la ley) sino de los encuentros con personas concretas y los afectos tejidos en los mismos. Está articulado al respeto hacia las necesidades de los otros y la mutualidad del esfuerzo por satisfacerlas.

En síntesis, la ética del cuidado se presenta como alternativa a una ética de la justicia basada en principios abstractos y universales. También se diferencia de una

33 Gilligan, Carol, In a Different Voice, Cambridge, Harvard University Press, 1982

34 Benhabib, Seyla «El otro generalizado y el otro concreto: la controversia Kohlberg-Gilligan y la teoría feministas", Teoría feminista y teoría crítica, editado por Seyla Benhabib y Drucilla Cornella, Valencia, Edicions Alfons el Magnànim, 1990, p. 119 
ética utilitarista basada en la búsqueda de beneficios y la competencia de intereses ${ }^{35}$. Como perspectiva ética, se centra en los vínculos que sostienen la vida de manera diaria y la importancia del cultivo de cualidades como la atención, la empatía, la escucha, la receptividad, no sólo en contextos como las relaciones de crianza o las amistades, sino en toda la vida social.

En el presente trabajo presentamos un abordaje relacional de la convivencia y del problema de la violencia, es en este sentido que nos preguntamos: ¿ Se puede gestar convivencia a partir del establecimiento de leyes y controles? ¿Qué relaciones existen entre la respuesta positiva al postulado anterior y una ética de la justicia? Si la ética del cuidado nos permite contextualizar, conocer, profundizar en las singularidades, así como cultivar vínculos afectivos en la vida social ¿qué sucede con las personas que no forman parte de nuestra red de relaciones?

\subsection{Sujetos de cuidado: ¿A quién cuidamos?}

\subsubsection{Cuidado de sí}

LA NOCIÓN DE CUIDADO DE sí ha sido indagada por Foucault ${ }^{36}$ a partir de sus estudios en torno a la filosofía de la Antigüedad. El destacado pensador afirmó que, aunque el precepto filosófico más difundido en relación a la filosofía de esta época es el principio délfico "conócete a ti mismo", este último era subsidiario de otro principio estructurante, el "cuidado de sî". Diversas escuelas filosóficas coincidían en la centralidad de esta noción que entretejía conceptos filosóficos, vida cotidiana, prácticas y ejercicios de transformación del sí mismo.

Desde el abordaje ético-relacional de la violencia que aquí proponemos, podemos elaborar a partir de la noción de cuidado de sí diferentes sentidos.

Un primer sentido del "cuidado de sí" es la transformación propia en base a los encuentros con otros. Los encuentros con los otros nos permiten el contacto con la alteridad, lo diferente a nosotros mismos. El yo no es inmune a esos encuentros. Los mismos tienen efectos sobre la subjetividad. Lo contrario sería afirmar una noción del yo como elemento aislado e independiente. El cuidado evidencia que necesitamos de los otros para vivir y existir. De este modo, el vínculo con el otro no es libre elección, es necesario. Por vivir y existir nos referimos a las múltiples dimensiones del ser humano: ser cien por ciento biológico y cien por ciento cultural. Por tanto más que en aislamiento, el ser humano se encuentra permanente-

\footnotetext{
35 Held, Virginia, The Ethics of Care: Personal, Political, and Global, op. cit.

36 Foucault, Michel, La hermenéutica del sujeto. Madrid, Ediciones de la Piqueta, 1987.
} 
mente afectado y afectando la trama vital a la que pertenece. Se trata de una trama compuesta por todo lo vivo. Un segundo sentido derivado del cuidado de sí, es el autocuidado. Como recuerda Foucault ${ }^{37}$ en el diálogo Alcibíades, el cuidado de sí en su forma prioritaria del conocimiento de sí, es condición para el gobierno de los otros y el gobierno de la ciudad. No se puede cuidar de otros sin cuidar de sí. Sin espacios, tiempos y disposición subjetiva para el cuidado de sí, el cuidado del otro es sacrificio. Es decir, relegación absoluta y plena del sí mismo. Podemos así establecer que el cuidado de sí no puede ser asimilado a egoísmo, ya que no es posible cuidar de otro sin cuidar de sí mismo. La asociación del cuidado de sí con el egoísmo sucede a partir de la influencia del cristianismo, según afirma Foucault ${ }^{38}$. Esta equivalencia entre cuidado de sí y egoísmo es también la propuesta de una gobernanza neoliberal que ha hecho del cuidado de sí una moral individualizada ${ }^{39}$. La misma convoca a las personas a ocuparse sólo de sí mismas y sus familias, abarcando con ello sus estilos de vida, estados físicos, en definitiva, una concepción "parroquial" del cuidado ${ }^{40}$.

\subsubsection{Cuidado del otro}

EN RESPUESTA A LA PREgUNTA ¿a quién cuidamos? la politóloga norteamericana Tronto afirma: "Cuidamos más a la gente más cercana emocional, física e incluso culturalmente. Así, una ética del cuidado podría volverse una defensa del hecho de cuidar sólo a la familia, a los amigos, al grupo, a la persona de la misma nación” ${ }^{41}$

Desde la perspectiva que sustentan nuestras investigaciones, para desarrollar una ética del cuidado es necesario contar con espacios comunitarios de encuentro, proximidad y contacto corporal y afectivo. En otros términos, se trata de gestar espacios y tiempos para sostener la "potencia de la vincularidad" 42 entre personas con trayectos vitales diversos. Los recorridos que señalamos anteriormente, nos permiten trazar una noción de cuidado que coloca en primera plana el carácter eco-inter-dependiente del ser humano ${ }^{43}$. Un ser vivo que sólo puede constituirse como tal

\footnotetext{
${ }_{37}$ Foucault, Michel, La hermeneútica del sujeto, op. cit.

38 Foucault, Michel, La hermeneútica del sujeto, op. cit.

39 Puig de la Bellacasa, María, Matters of care: Speculative Ethics in More Than Human Worlds, Minneapolis, University of Minnesota Press, 2017

${ }^{40}$ Joan Tronto, "There is an alternative: homines curans and the limits of neoliberalism". International Journal of care and caring, n.1, vol. 1 (2017): 27-43.

${ }^{41}$ Joan Tronto, "Más allá de la diferencia de género. Hacia una teoría del cuidado", Signs Journal of Women in Culture and Society, vol. 12, (2007).

42 De la Aldea, Elena, Los cuidados en tiempos de descuido, Santiago de Chile, LOM Ediciones.

43 De la Aldea, Elena, Los cuidados en tiempos de descuido, op. cit.
} 
a partir y a través del cuidado de otros y de los recursos que la naturaleza le brinda. Es en este marco que luego devendrá potencial cuidador de sí, de la naturaleza de la que es parte y de los otros.

Es entonces urgente contribuir a instalar como problemática central de nuestras comunidades la necesidad de contar con espacios para aprender modos de relacionarnos que contribuyan a la convivencia entre personas y con otras especies. En este sentido, el cuidado debe ser desanclado de la relación cuidador-niño para poder ser pensado en la vida social en su totalidad. Por lo tanto, la ética del cuidado de sí y del otro debe ser pensada en toda la trama social, también entre personas desconocidas. Nuestras sociedades deben promover tanto instancias que promuevan el conocimiento singular de las personas, como un cuidado sin estigmatizaciones ante los que nos resultan desconocidos.

\subsubsection{Cuidado de la comunidad}

LAS FORMULACIONES ANTERIORES nos conducen al cuidado de sí y del otro como un cuidado de la comunidad. En la Antigua Grecia, cuidar de sí era cuidar de la polis. Pues, en nuestra actualidad, cuidar de sí y de los otros es también cuidar la comunidad.

Cuidar de sí y cuidar de otros es tejer comunidad. En este sentido, la comunidad no existe como un mero agregado de individuos, sino cuando los seres humanos nos reconocemos como hebras de una trama vital mutuamente afectadas y afectantes. Para ello necesitamos adoptar una concepción multidimensional del ser humano que explore sus dimensiones emocionales y afectivas. La dimensión relacional y ética del concepto de cuidado pone de manifiesto que las necesidades humanas no se reducen a la alimentación, la higiene, la morada. Debemos incluir como necesidades el afecto y el encuentro cuerpo a cuerpo.

Desde el abordaje ético-relacional partimos de la consideración de que no podremos construir convivencia sin transformar nuestros modos de relacionarnos, con nosotros mismos y con los otros. Para ello es pertinente, como mencionamos anteriormente, generar dispositivos y espacios de encuentro que puedan establecer aprendizajes junto a otros en torno a las disposiciones subjetivas y modos relacionales dominantes en nuestra época, como lo son el miedo, la competencia, la desconfianza, el control. Tal como afirma Najmanovich ${ }^{44}$ dentro de una ecología

\footnotetext{
${ }_{44}$ Denise Najmanovich, "De la pedagogía de la crueldad a la ecología de los cuidados” (conferencia, VI Congreso de AUDEPP y X Congreso de FLAPPSIP, mayo de 2019).
} 
de los cuidados circula la confianza, la construcción colectiva del lazo amoroso que nos lleva a confiar y apoyarnos unos a otros.

Nuestras comunidades deben asumir el desafío del cultivo y fortalecimiento de los vínculos afectivos, desde un nosotros que no configure enemigos. Esta perspectiva que presentamos, se presenta en tensión con los abordajes que se basan en la seguridad concebida como la protección frente a un enemigo responsable de la inseguridad. El cuidado mutuo se gesta cada vez que cultivamos vínculos afectivos en la trama de todo lo vivo. En este sentido, resulta fundamental el fortalecimiento de las vecindades. ${ }^{45}$

El tipo de cuidado que estamos haciendo referencia en este apartado es aquel que liga, mezcla, funde y reúne sin obliterar las singularidades. Se trata de una comunidad capaz de acoger las diferencias y controversias desde una conciencia ecológica ${ }^{46}$ basada en la acción dialógica "que pone acento en la escucha y la valoración profunda acompañada de un hablar amoroso y apreciativo del otro" ${ }^{47}$

\subsubsection{Acuerdos Estado-Comunidad.}

El rol del Estado no es menor en este enfoque. Se trata de dar un giro decisivo de la función de protección externa, paternalista y garantista del contrato social, al ejercicio del cuidado como política de la práctica cotidiana. Su función será percibir, acompañar y cuidar el territorio, ofreciendo las formas, abriendo los espacios de encuentro, detectando los puntos de fuerza y potencia. El Estado deberá trabajar por el fortalecimiento y crecimiento de las comunidades, permitiendo que las personas creen y recreen su propio sentido de la vida social, generando las condiciones de confianza para la reparación de la trama humana. Desde este lugar las políticas públicas no se enfocarán ya en "gobernar a otros" sino en "habilitar y habitar con otros" apuntando a la promoción de los derechos de tercera generación, como el derecho a la paz ${ }^{48}$, entendimiento y cooperación mutua. Para ello será preciso tomar coraje y pasar de la sociedad del miedo y del control a la de la confianza y el amor, reconociendo nuestra participación, compromiso y deber inalienable e ineludible en esta construcción.

\footnotetext{
45 Maria Naredo, "Seguridad urbana y miedo al crimen", Polis, n. 2, vol. 1 (2001)

46 Edgar Morin, "El pensamiento ecologizado", Gazeta de Antropología, n. 12 (2006).

47 Perlo, Claudia y Costa, Leticia, Hacia una ética dialógica-ecológica, más allá del paradigma crítico, en Saber estar en las organizaciones. Una perspectiva centrada en la vida, el diálogo y la afectividad, dirigido por Claudia Perlo y Leticia Costa, Paraná, Editorial Fundación La Hendija, 2019, pp. 176

48 Sobre la articulación de construcción de la paz y ética del cuidado, sugerimos la consulta de la siguiente obra: Irene Comins Mingol, Filosofía del cuidar: una propuesta coeducativa para la paz, Barcelona: Icaria, 2009
} 
4. Síntesis de los tres abordajes

A CONTINUACión y a modo de síntesis de los conceptos hasta aquí abordados, presentamos un cuadro que busca facilitar la lectura y análisis de la complejidad que involucra la problemática planteada. 


\begin{tabular}{|c|c|c|c|c|}
\hline 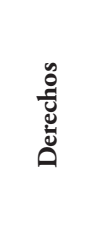 & 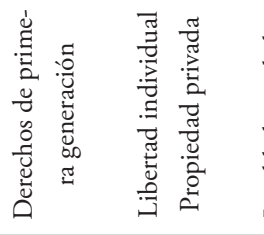 & 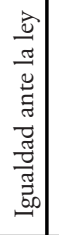 & 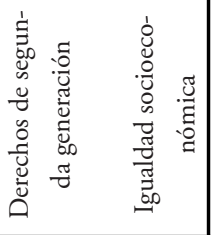 & 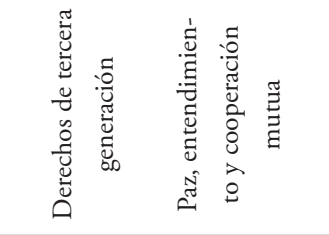 \\
\hline$\frac{\frac{\pi}{60}}{\frac{0}{0}}$ & 莺 & & 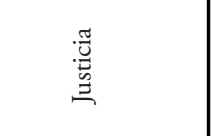 & 莺 \\
\hline 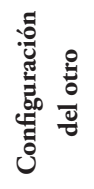 & 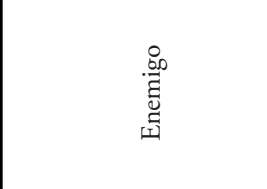 & & 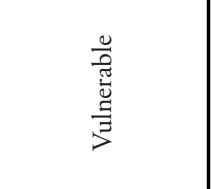 & 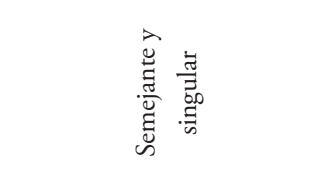 \\
\hline 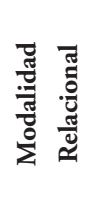 & 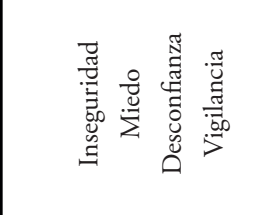 & & 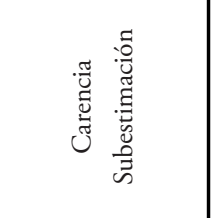 & 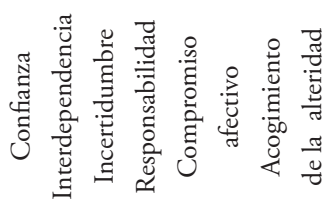 \\
\hline 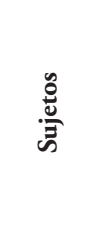 & 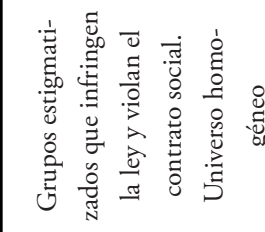 & & 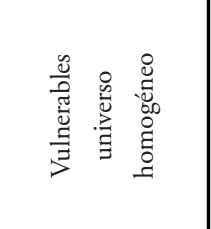 & 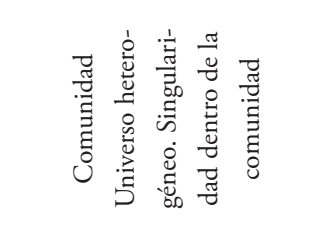 \\
\hline 施 & 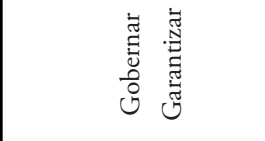 & & 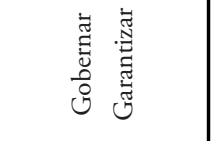 & 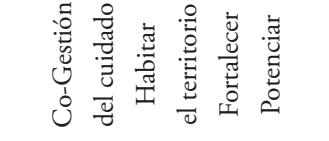 \\
\hline 菢 & 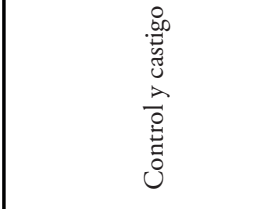 & & 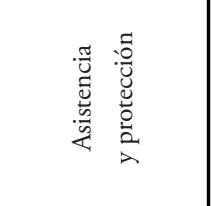 & 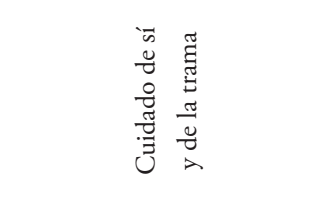 \\
\hline $\begin{array}{l}\frac{0}{\pi} \\
\frac{\pi}{\tilde{n}} \\
\frac{0}{2}\end{array}$ & 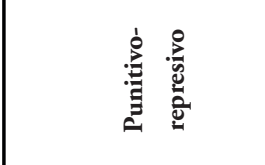 & & 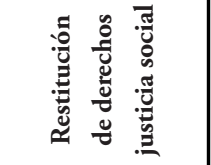 & 总 \\
\hline
\end{tabular}




\section{Apreciaciones finales}

A PARTIR DE LOS DESARRollos aquí presentados hemos buscado demostrar que los abordajes basados en la seguridad, hoy también llamados enfoques neopunitivistas $^{49}$ no han sido ni serán una política pública exitosa que posibilite vivir en con-vivencia. La configuración/fabricación del enemigo y el miedo como estrategia de gobierno, lejos de establecer el "orden" proclamado provocan un descontrol del control. Definitivamente cuidar no es vigilar y castigar ${ }^{50}$. Tampoco lo es denunciar y punir. La sospecha, la represión, el miedo y el castigo nunca fue ni será el modo de atender a los problemas de con-vivencia. El miedo no es un instinto, es una estrategia de gobierno del patriarcado, donde no hay lugar para la libertad, la identidad y la equidad. La violencia es la emergencia de una sociedad humana que extravió en su acervo biológico cultural las prácticas de cuidado, y la ausencia de cuidado se torna violencia.

La historia política nos ha mostrado que en muchas oportunidades en contextos de punición y control, la desobediencia ha sido un acto de coraje y de expresión de la propia identidad. Una desobediencia consciente, atenta más a sentimientos éticos situados vinculados al compromiso con uno mismo y con la trama, que al derecho objetivo y abstracto con pretensión de justicia universal. Consideramos que es la ética del cuidado, en tanto responsabilidad individual y colectiva, que va más allá de derechos y deberes punibles, puede devolvernos la condición de humanos.

En un contexto democrático sostener el modelo punitivo, en tanto generador de más violencia es altamente peligroso. Asimismo, el modelo de restitución de derechos y justicia social es necesario pero insuficiente, ya que no sólo necesitamos justicia para el sostenimiento de los vínculos en la vida social. Además de tratarnos de manera justa y organizar nuestras sociedades en base a principios de justicia como la igualdad, es necesario potenciar el cultivo de prácticas basadas en la escucha, la empatía, el respeto por las singularidades, la atención vital. Solemos destacar la importancia de estas cualidades en ciertos ámbitos: las familias, los contextos de amistad, las relaciones de crianza. En nuestro desarrollo, proponemos la importancia del desarrollo de una ética del cuidado no sólo en los contextos concebidos como "privados" sino en la vida en su totalidad ${ }^{51}$, compartida con otros que, en muchas ocasiones, nos resultan anónimos.

El modelo ético-relacional hoy constituye una topía (topos/espacio) que necesitamos urgentemente creer y crear. Ello exige un acto de confianza, donde

\footnotetext{
49 Eugenio Zaffaroni, 2020, Conferencia Virtual: Desafío de las cárceles Latinoamericanas. UNICEN.

${ }^{50}$ Foucault, Michel, Vigilar y castigar, op. cit.

51 Held, Virginia, The Ethics of Care: Personal, Political, and Global, op. cit.
} 
el control no tiene ningún lugar, ya que confianza y control nunca se encuentran. Como nos lo recuerda el destacado biólogo cultural Maturana la confianza muchas veces denostada, es inherente a la vida,. Confiar en la potencia de los vínculos requiere confiar en nuestros con-tactos, en el valor de la diversidad, en el cuidado de la vida como centro de nuestras ocupaciones y preocupaciones. La propuesta aquí presentada requiere que asumamos el coraje de apostar a una convivencia humana que sólo puede basarse en el cuidado de sí, de los otros y de todo lo vivo a partir de la acogida y la hospitalidad de la otredad. El filósofo y teólogo Kierkegaard afirmó que tener fe y confianza, es el coraje de sostener la duda. Sostenemos entonces esta duda: ¿ y si apostamos por la ética del cuidado? 


\section{REFERENCIAS BIBLIOGRÁFICAS}

Aczel, Amir. Entrelazamiento: el mayor misterio de la fisica. Barcelona: Editorial Crítica, 2008.

Benhabib, Seyla "El otro generalizado y el otro concreto: la controversia Kohlberg-Gilligan y la teoría feminista". En Teoría feminista y teoría crítica, editado por Seyla Benhabib y Drucilla Cornella, 119-150. Valencia: Edicions Alfons el Magnànim, 1990.

Boff, Leonardo. El cuidado esencial. Ética de lo humano, compasión por la tierra. Madrid: Editorial Trotta, 2002.

Boff, Leonardo. El cuidado necesario. Madrid: Editorial Trotta, 2012.

Böhm, David. La totalidad y orden implicado. Barcelona: Kairós, 1988.

Cohen, Gabriela. Amar y permanecer. Basado en el mito de Psiquis y Eros. Buenos Aires: Ediciones de la Luna, 2005

Comins Mingol, Irene. Filosofia del cuidar: una propuesta coeducativa para la paz. Barcelona: Icaria, 2009

Cullen, Carlos. Ética ¿¿dónde habitas?. Buenos Aires: Las cuarenta, 2019.

De La Aldea, Elena. Los cuidados en tiempos de descuido. Santiago de Chile: LOM, 2019.

Fernández Savater, A. (2016). "Del paradigma del gobierno al paradigma del habitar", en Blog Interferencias. Recuperado de https://www.eldiario.es/interferencias/paradigma-gobierno-habitar_6_491060895.html el 3 de marzo de 2019.

Fernández Savater, Amador (2018). "Tener necesidad de que la gente piense”, en Blog Interferencias. Recuperado de https://www.eldiario.es/interferencias/izquierda-pensamiento_6_816878305.html el 12 de diciembre de 2018.

Foucault, Michel. Vigilar y Castigar. Buenos Aires: Siglo XXI Editores, 1976.

Foucault, Michel. La hermenéutica del sujeto. Madrid: Ediciones de la Piqueta, 1987

Fuks, Saúl (2009). "FSPC: La facilitación sistémica de procesos colectivos. Artesanía de contextos focalizada en la promoción de la creatividad y de los procesos participativos en grupos, comunidades y redes", en Revista IRICE, N ${ }^{\circ} 20$, pp. 63-76

Gilligan, Carol. In a different voice. México: Fondo de Cultura Económica, 1982. 
Maturana, Humberto y Verden- Zöler, Gerda. Amor y Juego: Fundamentos olvidados de lo humano. Desde el patriarcado a la democracia. Buenos Aires: Granica, 2011.

Maturana, Humberto y Dávila, Ximena. El árbol del vivir. Santiago de Chile: MVP Editores, 2015.

Mead, George. Espiritu, persona y sociedad. Buenos Aires: Paidós, 1972.

Morin, Edgar "El pensamiento ecologizado", en Gazeta de Antropología, №12, 1996

Morin, Edgar. Introducción al pensamiento complejo. Barcelona: Gedisa, 1998.

Morin, Edgar. Los siete saberes necesarios a la educación del futuro. Caracas: IESALC-UNESCO, 2000.

Morin, Edgar. "La epistemología de la complejidad", en Gazeta de Antropología, $\mathrm{N}^{\circ} 20,2004$.

Najmanovich, Denise. "De la pedagogía de la crueldad a la ecología de los cuidados". Conferencia. VI Congreso de AUDEPP y X Congreso de FLAPPSIP, mayo de 2019.

Najmanovich, Denise. "Cuidadanía: ecología de los saberes y los cuidados". Conferencia. XVI Jornadas Nacionales de la Red de Psicopedagogía Garrahan, diciembre de 2019.

Naredo, María, "Seguridad urbana y miedo al crimen”, Polis, n. 2, vol. 1 (2001).

Perlo, Claudia. "Aportes del interaccionismo simbólico a las teorías de la organización”. Revista Invenio. n. 9 (2006): 89-107.

Perlo, Claudia. Hacer ciencia en el siglo XXI. Paraná: Editorial Fundación La Hendija, 2014.

Perlo, Claudia; De la Riestra, María; Costa, Leticia. "Organización, fragmentación y posibilidades de cambio: la brecha como vacío fértil”, en Cuadernos Ebape., n. 2, (2010): 247-259. https://doi.org/10.1590/S1679-39512010000200005.

Perlo, Claudia y Costa, Leticia "Hacia una ética dialógica-ecológica, más allá del paradigma crítico" en Saber estar en las organizaciones. Una perspectiva centrada en la vida, el diálogo y la afectividad, dirigido por Claudia Perlo y Leticia Costa, Paraná: Editorial Fundación La Hendija, 2019

Puig de la Bellacasa, María. Matters of care: Speculative Ethics in more than human worlds. Minnesota: University of Minnesota Press, 2018. 
Schutz, Alfred. Fenomenología del mundo social. Introducción a la sociología comprensiva. Buenos Aires: Editorial Paidós, 1972.

Todorov, Tzvetan. Frente al límite. México: Editorial Siglo XXI, 2004.

Toro Araneda, Rolando, Biodanza. Santiago de Chile: Cuarto propio, 2007.

Tronto, Joan,"Más allá de la diferencia de género. Hacia una teoría del cuidado". En: Signs Jornal of Women in Culture and Society, vol. 12 (2007).

Tronto, Joan,'There is an alternative: homines curans and the limits of neoliberalism". International Journal of care and caring, vol. 1 n. 1, (2017): 27-43. https://doi.org/10.1332/239788217X14866281687583

Zaffaroni, Eugenio. Conferencia Virtual: Desafío de las cárceles Latinoamericanas. UNICEN, 2020.

DOI: https://doi.org/10.15366/bp2021.27.012

Bajo Palabra. II Época. No 27. Pgs: 231-256 
